\title{
Assessment of emergency safety showers against proposed EU and ANSI standards
}

\author{
Martin. Burby*, Ghasem. G. Nasr*, Andrew. J. Yule*, \\ and Tony. Hughes** \\ *Spray Research Group(SRG), Institute of Materials Research (IMR), \\ School of Computing, Science and Engineering, Newton Building, \\ University of Salford, Manchester M5 4WT, United Kingdom \\ m.burby@salford.ac.uk \\ *Hughes Safety Showers Ltd, Managing Director, Stockport SK6 2SS
}

\begin{abstract}
This investigation was carried out with the cooperation of a major international safety shower manufacturer, Hughes Safety Showers Ltd. The first part of this study was to characterise various commercial safety shower heads with regard to their spray patternation, droplet sizes, droplet velocities and impact forces. The spray patternation of a number of shower head designs were compared against the proposed EU and American National Standard institute (ANSI) standard for plumbed in body showers. The results of this work showed that a large proportion of the shower head deigns failed to meet the proposed EU standard. The second part to this study was to determine the efficiency and effectiveness of the emergency safety shower head designs via a series of decontamination 'wash-off' tests on a mannequin, with a number of simulated hazardous substances applied to its surface.
\end{abstract}

\section{INTRODUCTION}

All emergency safety showers whether they are a single overhead spray, multi spray nozzle (or atomizer) or laboratory showers, including eyebath and eye/facewash units, must be designed and perform in accordance with the agreed European and/or US standards.

Emergency safety showers are a requirement in Great Britain, under the Health and Safety Regulations 1981 and the Control of Substances Hazardous to Health (COSHH) Regulations 1996, wherever employees are exposed to hazardous substances.

Typical hazardous substances that an employee may be exposed to, requiring the use of an emergency safety shower, are; acids, caustic substances, fire, dust particles, nuclear, biological, radiological and chemical agents. It is therefore essential that the emergency safety shower is capable of quickly and effectively washing off these various chemicals, all of which have differing material properties, which affect how quickly they can be washed off an individual.

To exemplify, the design of equipment, particularly the piping systems, must be in such a way that they give the required flow of water possible without causing injury to the user. They must also provide a continuous and effective flow of water at a minimum rated pressure. The spraying devices must be easily removable for maintenance and provide a uniform spray pattern and spray direction when re-installed back onto the shower system. Moreover, the water spray pattern for a single overhead spray must be such as to ensure that it is possible for a person in the shower to breathe normally and the velocity of the spray should also be low enough to be non-injurious to the user. 
There is limited literature freely available in the public domain on the effectiveness of different types of shower heads used in emergency safety showers and the best methods used to decontaminate an individual who has come into contact with a range of hazardous substances. Current practice for decontamination is to wash the effective area with water for at least 15 minutes [1], [2], [3]. Only when dealing with certain biological agents or oils it is recommended that hypochlorite or an oil dissolving solution is used in conjunction with water in the decontamination process.

Decontamination methods have been evaluated by the ministry of defence for a range of biological agents but such literature is not freely available. The UK fire brigade has also commissioned work into the effectiveness of decontamination showers to decontaminate firefighters in chemical protective suits for a range of non hazardous materials [4], however such research has not evaluated the effectiveness of different types of shower head designs in the decontamination process. In other areas, like fire suppression [5], [6], [7], [8], droplet size and water distribution has been thoroughly investigated for a range of different shower heads which have brought about improved nozzles to suppress fires.

This paper describes experiments that have been carried out to explore the performance characteristics of different shower head designs with regard to water distribution with respect to EU and ANSI standards, along with impact force and droplet size measurements. A number of these commercial shower head designs were further evaluated as to their relative performance in decontaminating a mannequin of a number of simulated hazardous substances of varying viscosities and solubilities.

\section{PERFORMANCE STANDARDS FOR SAFETY SHOWERS}

The proposed EU performance standards [9] for plumbed in safety showers state that a constant flow of water supplied by the body shower shall be a minimum of $60 \mathrm{l} / \mathrm{min}$ at a flow pressure of a minimum of $1 \mathrm{bar}$ measured where the shower is connected to the water system. The safety shower shall be capable of delivering this supply for a minimum of 15 minutes. As shown in Figure 1, at a distance $700 \mathrm{~mm}$ below the shower head, $50 \%, \pm 5 \%$ of the volume of water delivered shall fall in a circle with a radius of $200 \mathrm{~mm}$; the water level in the individual containers in this circle shall not deviate by more than $30 \%$ from the mean value. At this measuring level, the area reached by $95 \%$ of the water shall be limited to a circle with a radius of $400 \mathrm{~mm}$. The spray pattern shall be such as to ensure that it is possible for a person in the body shower to breath normally and the velocity of the spray shall be low enough to be non-injurious to the user.

The American Standard for plumbed in safety showers requires that showers must meet the American National Standard Institute (ANSI) for Emergency Eyewash Equipment [10]. Emergency showers shall be designed and located so that a flushing liquid column is provided that is not less than $2083 \mathrm{~mm}$ nor more than $24380 \mathrm{~mm}$ in height from the surface on which the user stands. Plumbed and self contained shower equipment shall be capable of delivering flushing fluid at a minimum of $75.7 \mathrm{l} / \mathrm{min}(20 \mathrm{gph})$ for a minimum of 15 minutes. The spray pattern shall have a minimum diameter of $508 \mathrm{~mm}$ at $1524 \mathrm{~mm}$ above the surface on which the user stands, and the centre of the spray pattern shall be located at least $406 \mathrm{~mm}$ from any obstruction. The flushing fluid shall be substantially dispersed throughout the pattern, as shown in Figure 2.

\section{SHOWER HEADS TESTED}

Eight commercial shower heads were tested, a number were chosen for further testing with the aim of assessing the relative performances between the designs. This included, droplet size and impact force measurement and wash off tests. The designs were categorised based upon the type of mechanism by which the spray is produced, as shown in Figure 3. 


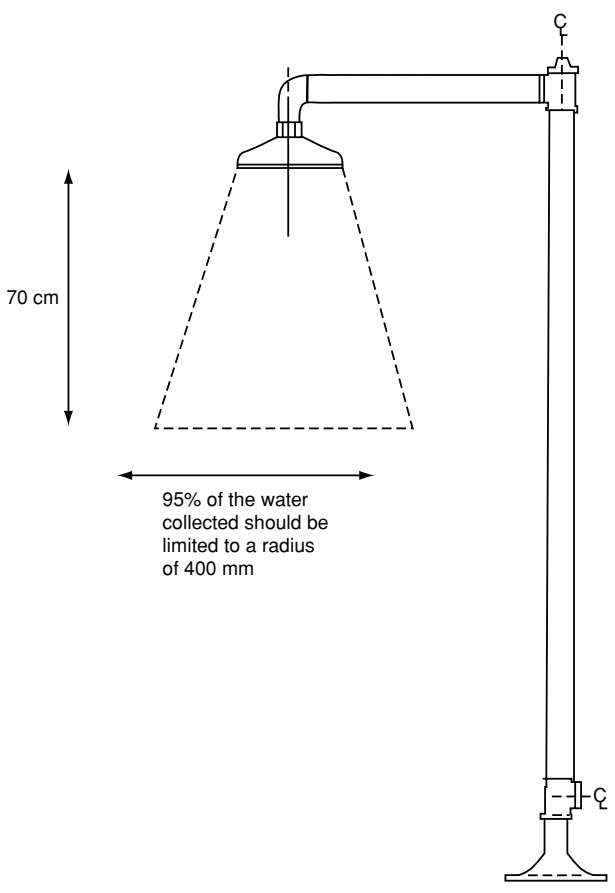

Figure 1 EU plumbed in shower standards.

The shower rose categories are made up of shower heads with either a flat or domed plate with a number of perforated holes, these come in a variety of patterns and hole sizes. The radial distribution of the spray is highly dependent upon the diameter of the shower head. Three shower rose types were tested, A_rose, B_rose and C_rose.

The nozzle category of shower head have a single orifice with a diffuser plate that has a number of angled slots, which are used to affect the radial distribution of the spray. The nozzle shown in Figure 3 has a ' $v$ ' slot cut into the exit orifice, this is to ensure the nozzle is fully drained of water to prevent freezing after operation. Two nozzle types were tested, A_nozzle and B_nozzle.

The filmer category of shower head uses a combination of a filmer plate and shower rose to produce the spray. The filmer plate causes the flow to attach itself to the plate, thus sending the flow radially outwards, whilst the central plate consists of a number of perforated holes. Three types of filmer shower head were tested; A_filmer, B_filmer and C_filmer.

\section{EXPERIMENTAL SET-UP}

To evaluate the different shower head designs with regard to the ANSI and proposed EU performance standards it was necessary to develop a test rig that was flexible enough to allow the shower heads to be adjusted to the EU and ANSI heights in relation to the water collection module (patternator). The test rig also had to have sufficient room to accommodate a patternator and a mannequin for the decontamination tests. The spray from the shower heads had to be contained and there had to be optical access to enable drop size measurements to be performed using a Pulse Photonics fast image grabbing system, and access for the camera during decontamination tests. 


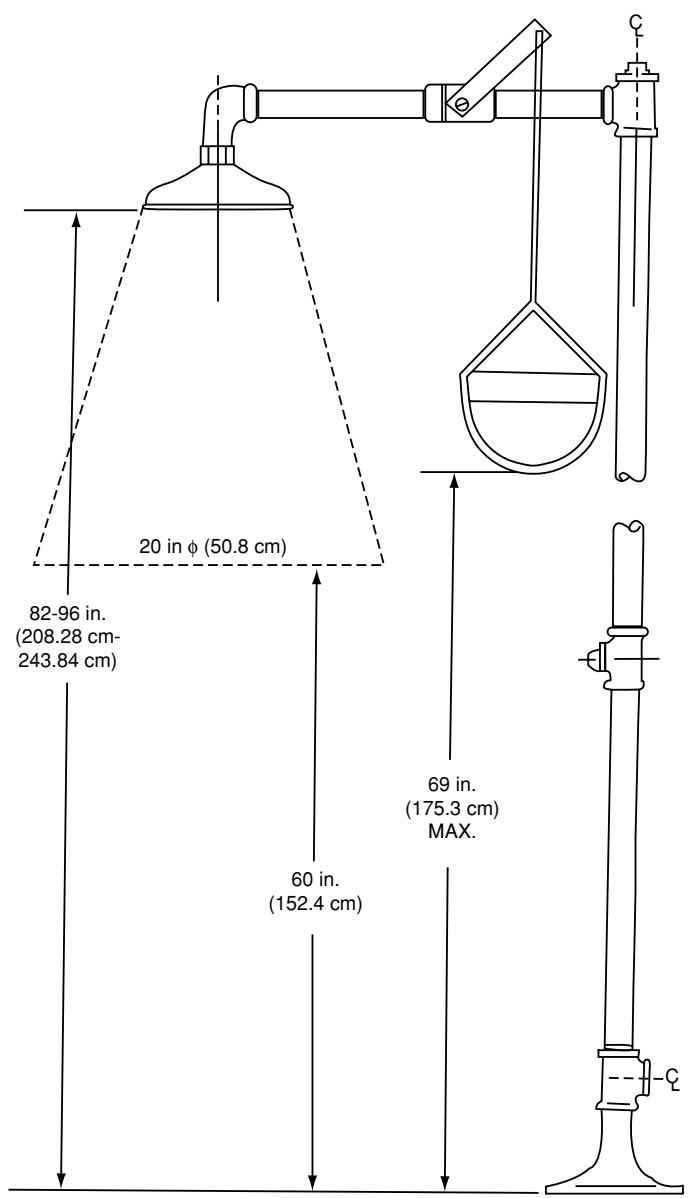

Figure 2 ANSI plumbed in shower standards.

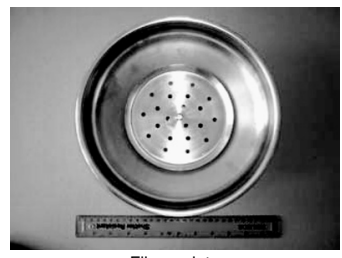

Filmer plate

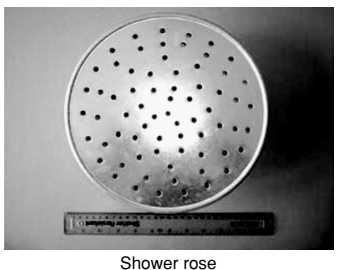

Shower rose

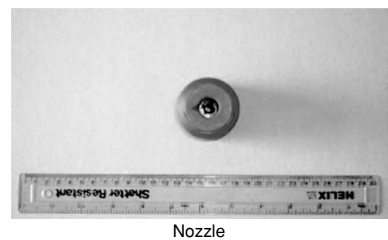

Figure 3 Shower head categories. 
The test rig was constucted from aluminum box sections which incoporated grooves which allowed the pattternator and shower head support frame to be moved vertically. Perspex sheets were attached to three sides of the test rig to contain the spray, as shown in Figures 4 and 5. Water was supplied fom a header tank, which also incorporated a heater, which allowed the temperature of the water supply to be regulated. A pump was used to obtain the desired flow rates of 60 and $75 \mathrm{l} / \mathrm{min}$ and a rotameter was used to set the flow rate which was controlled by a valve. Water from the shower head was collected in a sump which discharged to the factory drain.

\subsection{PATTERNATION TESTS}

Patternation test were carried out to measure the radial and circumferential distribution of the spray produced by the different shower head designs. The results of these measurements were then compared to the EU and ANSI standards to see as to whether the shower head designs met the required spray distribution. The patternator is shown in Figure 6. The patternator consists of 17 collection sectors. The centre has a collection diameter of $200 \mathrm{~mm}$ and subsequent sectors are in annuli increasing in diameter by $200 \mathrm{~mm}$ increments up to the outer diameter of $1000 \mathrm{~mm}$. Water that is collected in these sectors passes through a drain hole into 10 litre measuring receptacles located under the patternator. The height of the patternator in relation to the shower head can be adjusted using the adjustable arms that the patternator is mounted upon, as shown in Figure 4.

During operation the shower head height was adjusted vertically in relation to the patternator to obtain the desired EU or ANSI height of $700 \mathrm{~mm}$ or $910 \mathrm{~mm}$ respectively. The height was taken from the bottom of the showerhead to the top of the patternator. The valve was opened for 30 seconds and the required water flow rate was set (EU flow rate $60 \mathrm{l} / \mathrm{min}$, ANSI flow rate $751 / \mathrm{min}$ ). The volumes of water collected in the receptacles were recorded after allowing a suitable time period for the water to drain from the patternator into the receptacles.

The main source of error encountered during the patternation tests was the time between starting the stopwatch and obtaining the required flow rate. This usually took 2 seconds before the target flow rate was achieved. In that time period the flow rate may have fluctuated between an estimated $\pm 5 \mathrm{l} / \mathrm{min}$ off the target value.

During the post-processing the total flow rate collected in all the 5 circuits was compared with the total theoretical EU value of $60 \mathrm{l} / \mathrm{min}$. This check was particularly useful for the shower rose designs, which produces no overspray. Collected values were within $\pm 5 \%$ of the theoretical value. If this was not achieved the patternation tests were repeated. For the nozzle designs there was a reduction in the water volume collected from the thoeretical value due to the overspray not being collected, therefore this value could be up to $\pm 8 \%$ of the theoretical value.

\subsection{IMPACT FORCE}

Force measurements were taken to assess the differences in the impact force produced for; B_nozzle, A_rose, B_rose, C_rose and A_filmer, at a number of radial positions through the spray. Both the EU and ANSI standards stipulate that the spray produced by the shower head should be of a low enough velocity to be non-injurious to the user. The components for the force measurements can be seen in Figure 7. The test equipment consisted of a load transducer upon which a $30 \mathrm{~mm}$ diameter circular collection surface was attached. This was inclined at $5^{\circ}$ from the horizontal to allow the water to drain off. A mounting bracket was attached to the sensor to allow it to be fixed to the patternator during the force measurement tests. 

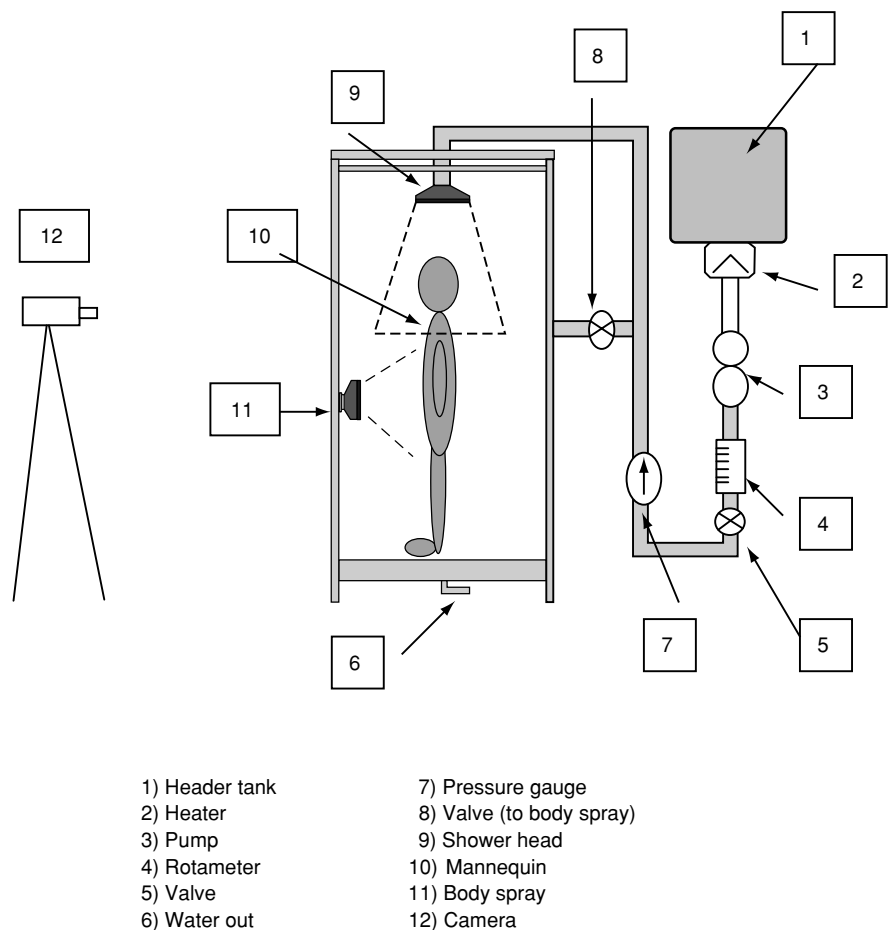

7) Pressure gauge

8) Valve (to body spray)

9) Shower head

4) Rotameter 10) Mannequin

6) Water out

11) Body spray

12) Camera

Figure 4 Schematic of the wash off test equipment.

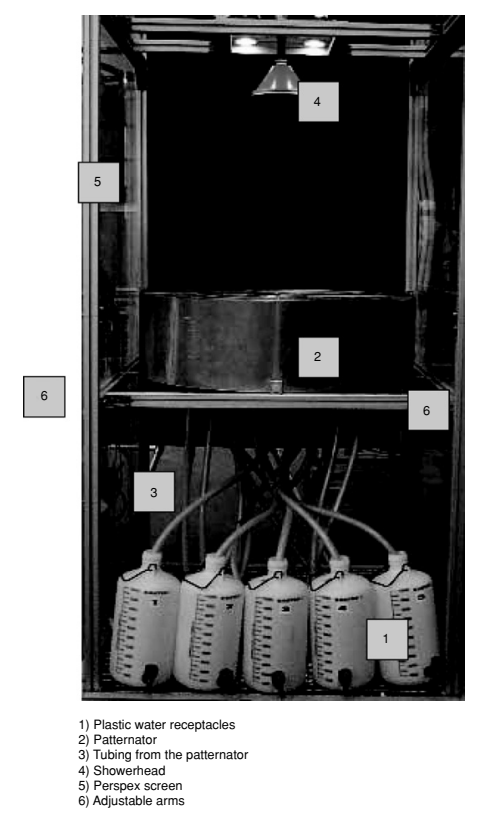

Figure 5 Test rig. 


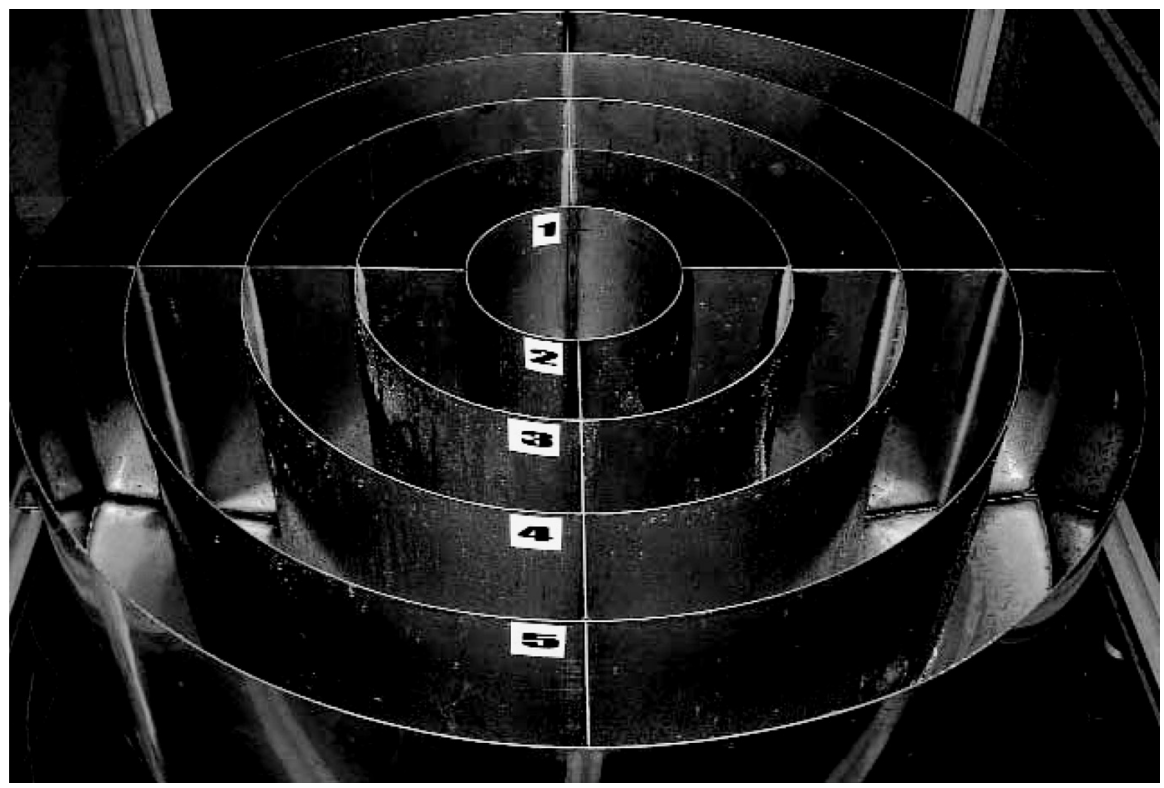

Figure 6 Patternator.

The sensor was connected to a data logger that recorded the load seen by the sensor every 3 seconds and could be reviewed in the post-processing package over a period of time specified by the operator.

The readings obtained from the data logger were related to force by calibration by placing a number of known weights on the collection plate and recording the values given by the sensor. This produced a linear curve of sensor readings and weight which could be related to the average reading obtained during the 5 minute test period.

The off-set value was recorded before and after each test to obtain how much drift had occurred over the test period. During the tests this accounted to \pm 0.05 N. Despite the inclined collection plate to minimise standing water, an estimated $0.08 \mathrm{~N}$ force could result from residual water on the plate.

\subsection{DROPLET SIZE}

Droplet size measurements were taken for A_nozzle and B_rose using a Pulse Photonics system. This is a non intrusive technique which allows images to be captured by a CCD camera head and transferred to the PCI board in the computer. The software installed on the computer 'CamWare' then allows for the set up and analysis of the images. Droplet size measurements were taken $700 \mathrm{~mm}$ from the shower head and at a number of radial distances through the spray. Figure 8 illustrates the set up of the Pulse Photonics equipment. The CCD camera had a standard C mount objective lens and was connected to the PCI inteface of the computer by double-coaxial cables. The computer was connected to the pulse generator which allowed the duration of the pulse of light to be varied from 5-500 ms. The pulse genertor was connected to the Xenon flash tube. To trigger the flash and to capture an image there was a manual trigger connected to the pulse generator. 


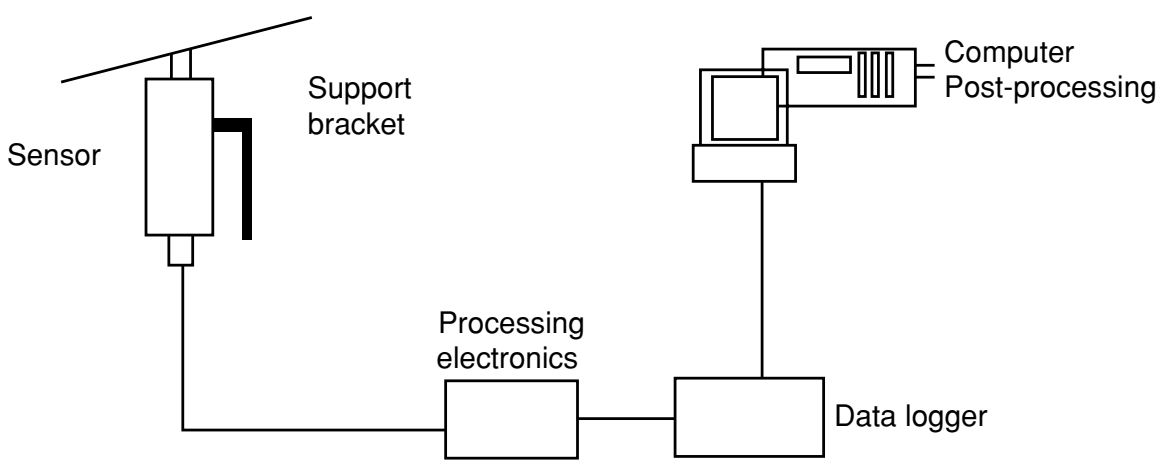

Figure 7 Schematic of the force measurement equipment.

Images captured by the CCD camera contain a number of droplets and the software allows the user to manipulate virtual cross hairs which are then placed at positions on the boundary of the droplet. The software then calculates the height and width of the droplet, based upon the field of view length scale which has been inputted. During operation the height and width of 30 droplets at each radial position through the spray were recorded and exported into Excel and the mean droplet size and standard deviation (std) were calculated. This was done at three radial positions through the spray and at a distance of $700 \mathrm{~mm}$ from the shower head. The main source of error was in deciding the boundaries of the droplet, this was estimated to be \pm 5 microns for both width and height of the droplet.

\section{RESULTS}

\subsection{PATTERNATION RESULTS}

From the patternation results, as shown in Table 1, the shower roses have good radial and circumferential water distribution but tend to have a narrow spray pattern, with no water collected beyond a diameter of $40 \mathrm{~mm}$. The nozzle designs have reasonable radial and circumferential water distribution, but they can deliver too much over-spray (greater than $1000 \mathrm{~mm}$ in diameter). The filmer designs can produce very poor radial and circumferential water distribution if the water does not film all the way round the filmer surface. It was also observed that a number of the central holes do not discharge full, resulting in the water being ejected from the holes at large angles from the normal. This results in not enough water being collected within a diameter of $200 \mathrm{~mm}$.

All the shower heads meet the less stringent ANSI standard, as shown in Table 2 of delivering a spray with a minimum diameter of $500 \mathrm{~mm}$ at a distance of $900 \mathrm{~mm}$ from the shower head, however the filmer and shower rose designs are close to this limit. Of particular concern is that of all of the commercially available shower heads tested only one shower head (B_nozzle) passed the proposed EU standard.

\subsection{IMPACT FORCE RESULTS}

Spray force measurements were taken at the EU flow rate of $601 / \mathrm{min}$. The measurements were taken over 5 minutes and an average force was calculated for each location. The readings were taken at 4 radial locations through the spray, starting from the centre of the spray and out to a radial distance of $350 \mathrm{~mm}$.

At the EU flow rate, as shown in Figure 9, the three rose designs had similar force profiles with a relatively flat profile across the spray, which would be expected due to the design 


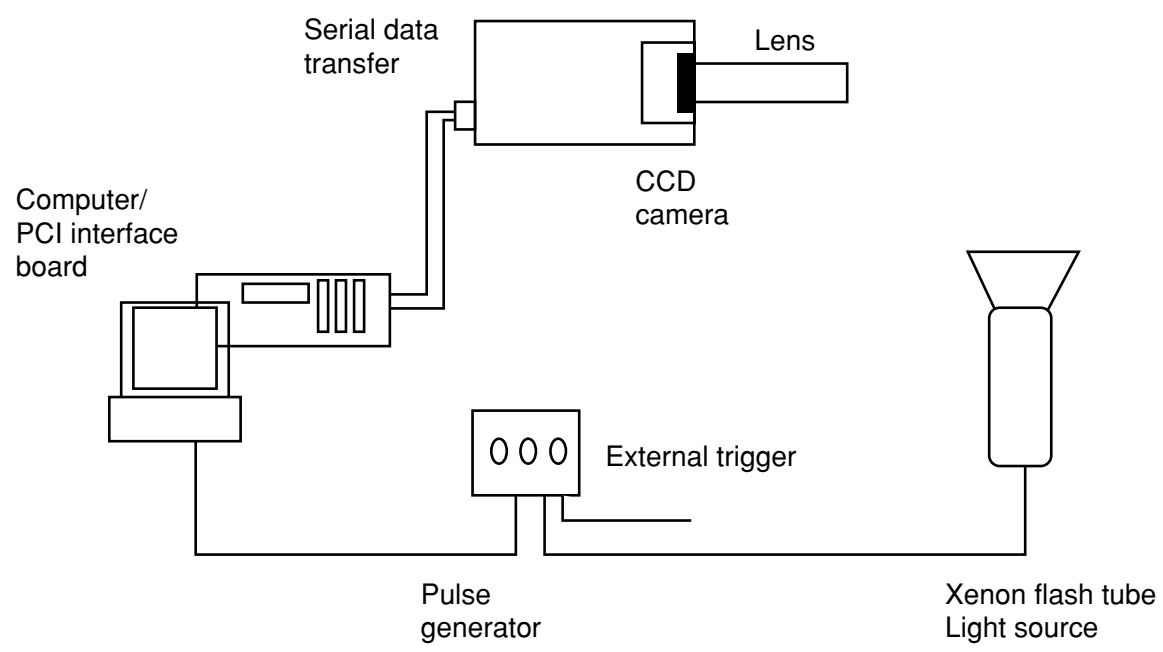

Figure 8 Schematic of the set up of the Pulse Photonics equipment.

having a relatively uniform spray profile. The nozzle design produced most force at the centre of the spray, which then reduced near the spray boundaries. The filmer design had a high force at the centre of the spray from the jets from the central holes, and then reduced until a radial distance of $150 \mathrm{~mm}$ before rising again as water from the filmer surface took affect. All the shower head designs produced similar orders of magnitude of force.

\subsection{DROPLET SIZE RESULTS}

Figure 10 shows the mean width and height of the droplets for the rose design (B_rose) at a number of radial positions through the spray along with the standard deviation. The width and height of the droplets both increase from the centre of the spray to the outer edge. The standard deviation profile through the spray is fairly flat, indicating that the spread of droplet sizes does not vary greatly through the spray. Figure 11 shows the droplet data for A_nozzle. As expected due to the higher kinetic energy of the spray from the nozzle, a finer more uniform spray is produced than for the shower rose.

Figure 12 shows the ratio of droplet width to height at a number of radial positions through the spray. The ratio indicates how spherical the droplets are. For both the nozzle and the shower rose the droplets become less spherical moving from the centre of the spray to the outer edge, with the nozzle producing a more spherical spray. Results from the wash off tests will help determine whether this is a beneficial characteristic in decontaminating a person who has come into contact with a hazardous substance.

\section{WASH OFF TESTS}

The wash off tests were performed to quantitatively assess the relative performances of nozzles, filmer and shower rose designs in decontaminating a person who has come in to contact with a hazardous substance.

A methodology was devised to categorise various hazardous substances according to how difficult they would be to wash off an individual who has come in to contact with them. This was expressed as a 'wash off rating' based upon the viscosity and the solubility of the substance. For these hazardous substances a non hazardous substance was chosen to replicate the hazard which had similar viscosity and solubility as the hazard, and were used during the decontamination tests (wash off tests). 
Table 1 Patternation results (EU conditions)

\begin{tabular}{|c|c|c|c|}
\hline Type & $\begin{array}{l}\text { Shower } \\
\text { head }\end{array}$ & $\begin{array}{l}\% \text { Water collected } \\
\text { within a radius of } \\
200 \mathrm{~mm}^{*}( \pm 5 \%)\end{array}$ & $\begin{array}{l}\text { Pass/Fail EU } \\
\text { standard }\end{array}$ \\
\hline \multirow{3}{*}{ Shower rose } & A_rose & 42 & Fail \\
\hline & B_rose & 41.8 & Fail \\
\hline & C_rose & 15 & Fail \\
\hline \multirow{2}{*}{ Nozzle } & A_nozzle & 42 & Fail \\
\hline & B_nozzle & 48 & Pass \\
\hline \multirow{3}{*}{ Filmer surface } & A_filmer & 90 & $\begin{array}{c}\text { Fail } \\
\text { (circumferential distribution) }\end{array}$ \\
\hline & B_filmer & 4 & Fail \\
\hline & C_filmer & 55 & $\begin{array}{c}\text { Fail } \\
\text { (circumferential distribution) }\end{array}$ \\
\hline
\end{tabular}

* The standard requires $50 \%$ of the water to be collected within a radius of $200 \mathrm{~mm}$.

Table 2 Patternation results (ANSI conditions)

\begin{tabular}{|c|c|c|c|c|}
\hline Type & $\begin{array}{c}\text { Shower } \\
\text { head }\end{array}$ & $\begin{array}{c}\% \text { Water collected } \\
\text { within a radius } \\
\text { of } 200 \mathrm{~mm}( \pm 5 \%)\end{array}$ & $\begin{array}{l}\text { Diameter of } \\
\text { spray greater } \\
\text { than } 500 \mathrm{~mm}\end{array}$ & $\begin{array}{c}\text { Pass/Fail } \\
\text { ANSI } \\
\text { standard }\end{array}$ \\
\hline \multirow{3}{*}{ Shower rose } & A_rose & 28 & $\sqrt{ }$ & Pass \\
\hline & B_rose & 18 & $\sqrt{ }$ & Pass \\
\hline & C_rose & 6 & $\sqrt{ }$ & Pass \\
\hline \multirow{3}{*}{ Nozzle } & A_nozzle & 66 & $\sqrt{ }$ & Pass \\
\hline & B_nozzle & 45 & $\sqrt{ }$ & Pass \\
\hline & A_filmer & 82 & $\sqrt{ }$ & Pass \\
\hline \multirow{2}{*}{ Filmer surface } & B_filmer & 2 & $\sqrt{ }$ & Pass \\
\hline & C_filmer & 64 & $\sqrt{ }$ & Pass \\
\hline
\end{tabular}

Four non hazardous substitutes were chosen to represent a range of hazardous substances from acids to fuels. They also represent a broad spectrum in the wash off rating based upon their water solubility and kinematic viscosity. The four model substitutes that were applied to the mannequin are shown in Table 3.

The test equipment for the wash off test is shown in Figure 4. The manequinn was placed in the test rig with the centre of its head in line with the centre of the shower head. The height of the shower head was adjusted so that the distance between the bottom of the shower head and the top of mannequin was $300 \mathrm{~mm}$. The flow of water was controlled through a rotameter and the temperature of the water supplied to the showerhead was regulated by an immersion heater situated in the header tank.

A body spray was included in further wash off tests to examine the effectiveness of a shower head and body spray combination, as shown in Figure 13. The body spray was mounted $700 \mathrm{~mm}$ from the base of the platform and $400 \mathrm{~mm}$ from the centre of the mannequin. Water was supplied to both the showerhead and body nozzle via a ' $\mathrm{T}$ ' piece, with a total water flow rate of $110 \mathrm{l} / \mathrm{min}$ (as stipulated in the proposed EU standard). 


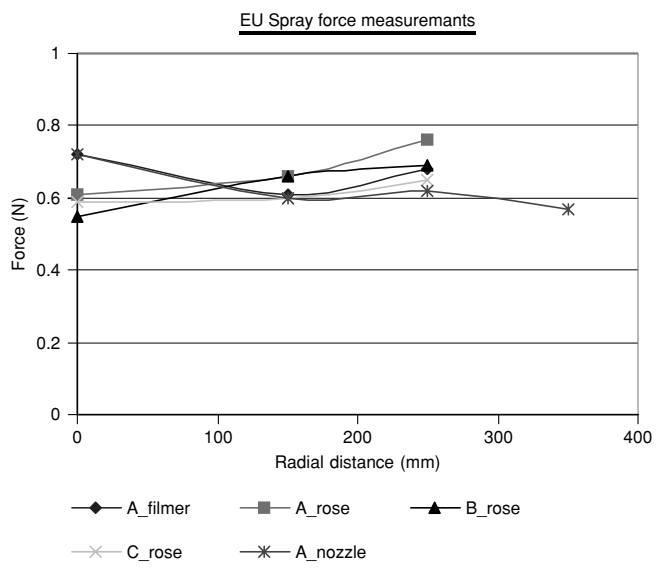

Figure 9 Spray force measurements (EU condition).

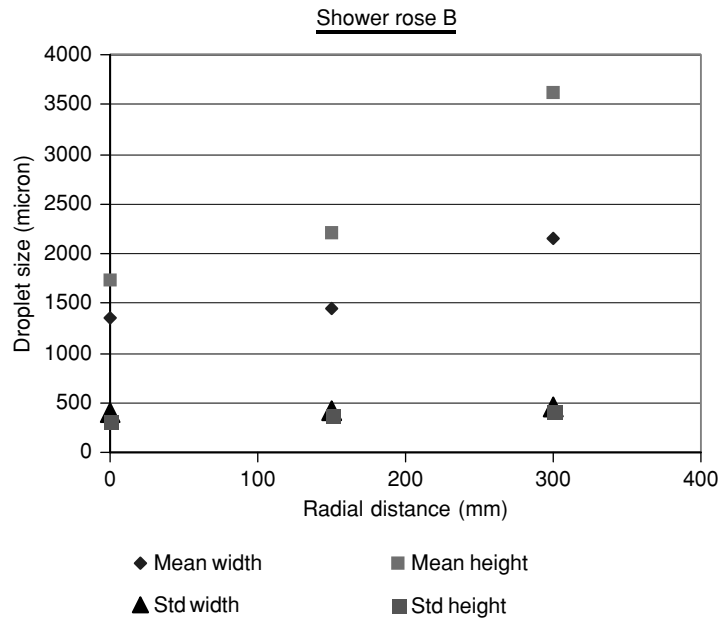

Figure 10 Droplet size (EU condition).

A mannequin was used as a human substitute for the wash off tests, the dimensions being a height of $1900 \mathrm{~mm}$ and shoulder width of $580 \mathrm{~mm}$. Initial tests were with a simulated latex skin being applied to the surface of the mannequin, however due to the force of the spray the latex was blasted off in places and created an uneven finish. It was decided that subsequent tests would be made without the skin substitute. Therefore the tests represent a comparison of wash off effectiveness of the shower head designs, rather then a time to decontaminate an individual of a particular hazardous substance.

A digital camera (Fuji Finepix f402, 3 million megapixels) was used to capture images of the washoff tests with the camera sited $2600 \mathrm{~mm}$ from the manequin and at a height of 800 $\mathrm{mm}$. Pictures were recorded over a 5 minute period in the following intervals;

- $\quad$ Picture of coated manequinn prior to decontamination test

- 20,40 seconds

- $1,2,3,4,5$ minutes 


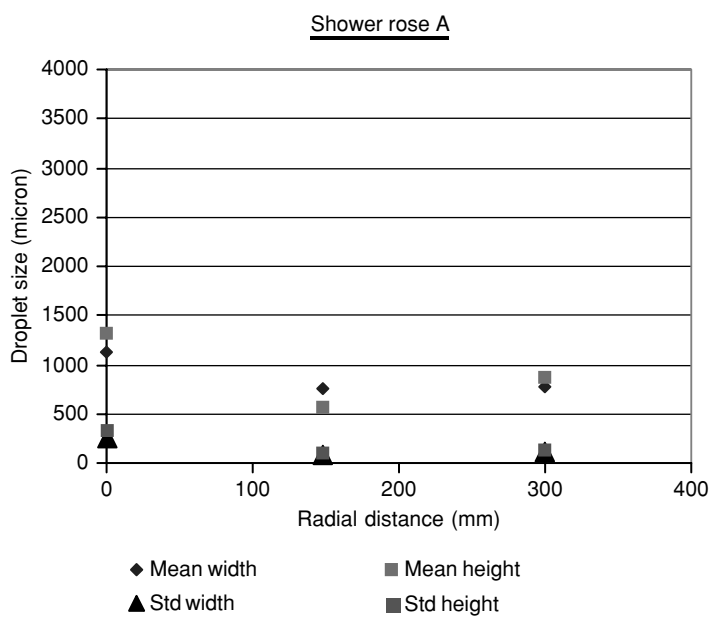

Figure 11 Droplet size (EU condition).

The main sources of error for the wash-off tests were;

- $\quad$ Ensuring a uniform coating applied to the mannequin for each of the tests. This was achieved by painting the body parts with known quantities of the simulated hazardous solution

- Observation of the time to completely decontaminate the body parts, the error was estimated to be \pm 3 seconds.

\subsection{WASH OFF TESTS PERFORMED}

Three shower heads were chosen for the main wash off tests, A_nozzle, B_rose and A_filmer. The tests were conducted at the proposed EU flow rate of $60 \mathrm{l} / \mathrm{min}$ for the single shower head and $110 \mathrm{l} / \mathrm{min}$ for the shower head and body spray combination, with the test conditions shown in Table 4.

\section{RESULTS OF THE WASH OFF TESTS}

The main findings that can be taken from the results of the wash off tests shown in Table 5 are;

- The arms were the first part of the mannequin to be decontaminated for all three shower head designs, followed by the torso. The parts of the body that took the longest were either the lower torso or the legs (usually the upper leg).

- For a hazard like Sulphuric acid, simulated using Beer (based upon similar material properties of viscosity and solubility), all three designs proved effective and had similar decontamination times.

- $\quad$ Olive oil was used to simulate fuel oil and proved to be the hardest to wash off of all the simulated non hazardous substitutes, even more so than Honey, which is probably due to it being non soluble.

The nozzle deign performed well with the simulated hazard substitute, beer. However the nozzle did not perform as well as the filmer and rose design for the other simulated hazard substitutes, Honey, Syrup and Olive oil. One reason for this may be due to the sprays 


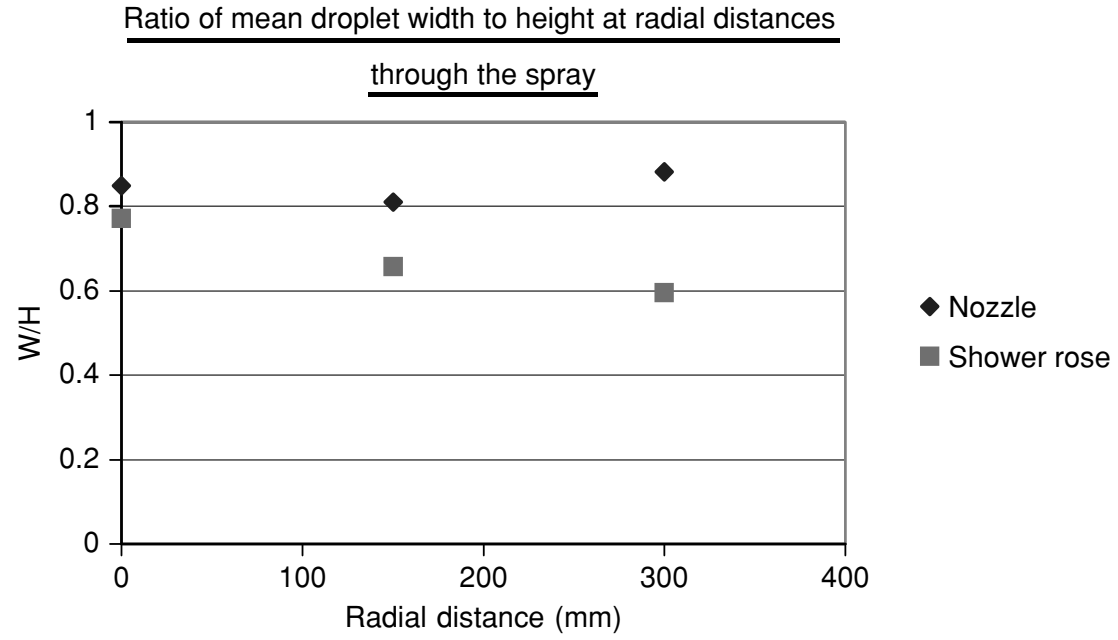

For a width to height ratio $(\mathrm{W} / \mathrm{H})$ of unity, the droplet would be spherical.

Figure 12 Ratio of mean droplet width to height.

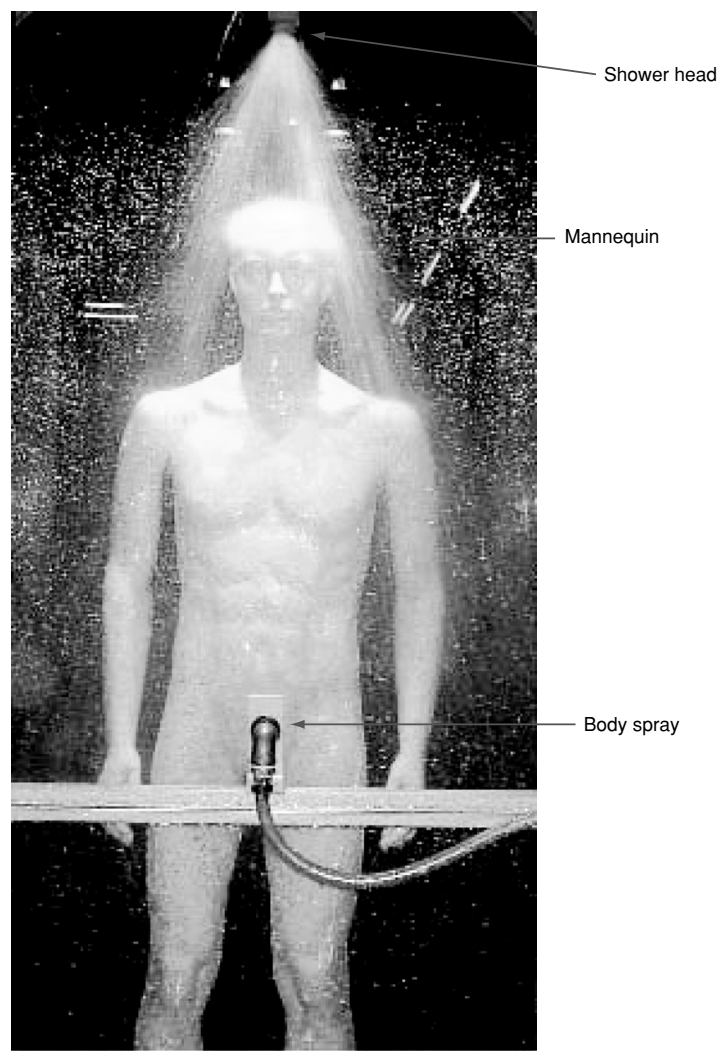

Figure 13 Schematic of the wash off test equipment. 


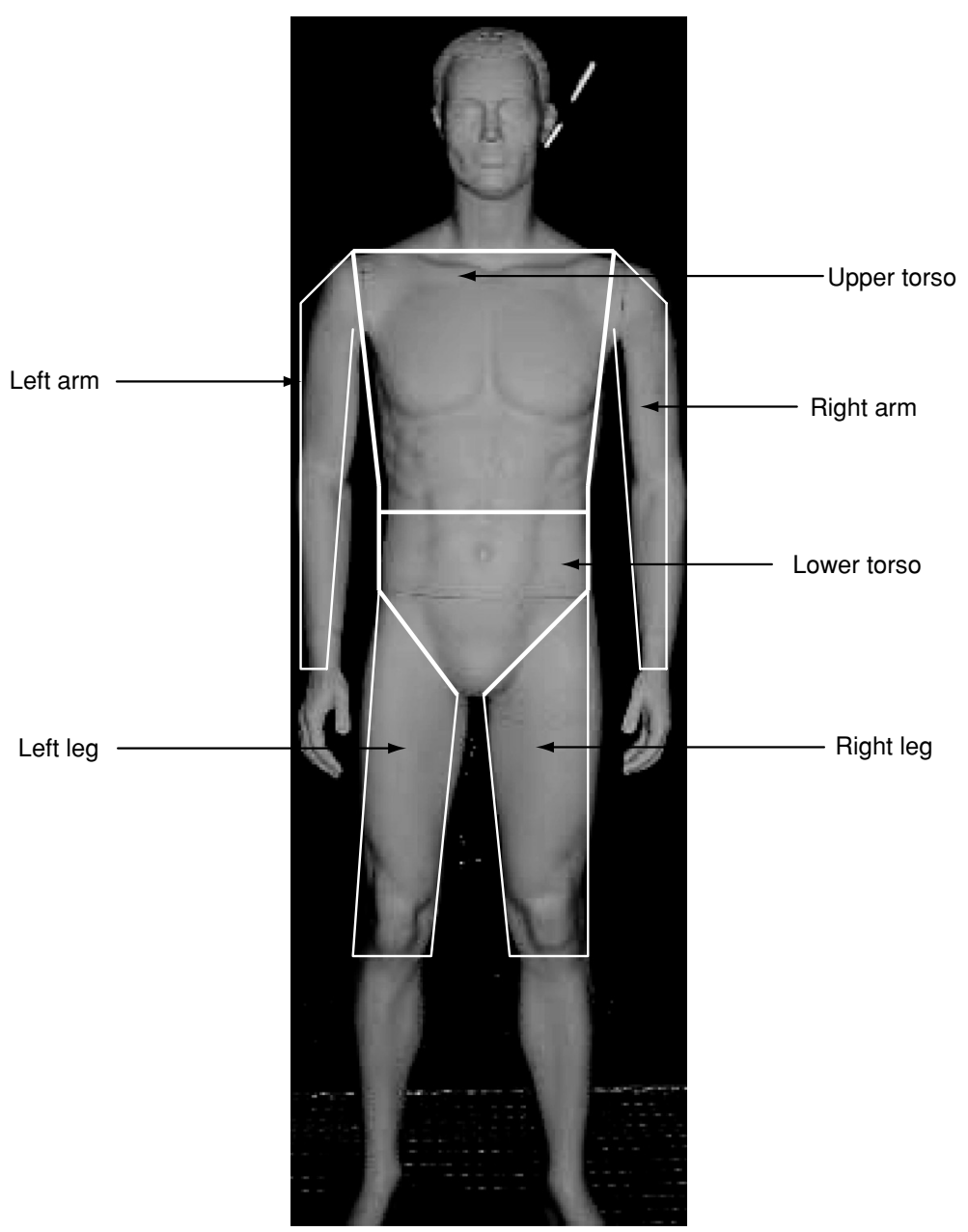

Figure 14 Sectors of the mannequin.

interaction with the mannequin. The nozzle design produces a jet of water, which is concentrated at the head. The force measurements show the impact force of the spray is higher in this central region than for the other two designs of shower head. The effect is that a significant amount of the water bounces off the mannequin rather than impacting the mannequin and then flowing round the body in a flushing action taking away the contaminant, as with the filmer and rose design. In the case of the shower rose the larger droplet sizes may also be contributing in reducing decontamination times when compared to the nozzle design, as the larger droplet size will be delivering a greater cleaning coverage on the surface of the mannequin.

\subsection{SHOWER HEAD AND BODY SPRAY}

A body spray was included in further wash off tests to examine the effectiveness of a shower head and body spray combination. The body spray was mounted at a height of $700 \mathrm{~mm}$ from the base of the platform and $400 \mathrm{~mm}$ from the centre of the mannequin. Water was supplied to both the showerhead and body nozzle via a 'T' piece, with a total water flow rate of $110 \mathrm{l} / \mathrm{min}$. 
Table 3 Simulated hazardous substitutes

\begin{tabular}{lcccc}
$\begin{array}{l}\text { Wash off } \\
\text { rating }\end{array}$ & $\begin{array}{c}\text { Simulated } \\
\text { hazard }\end{array}$ & $\begin{array}{c}\text { Non hazardous } \\
\text { Substitute }\end{array}$ & $\begin{array}{c}\text { Viscosity } \\
(\mathbf{c P})\end{array}$ & $\begin{array}{c}\text { Solubility } \\
\left(\mathbf{g} / \mathbf{1 0 0 m l @ 2 5} \mathbf{C}^{\circ} \mathbf{C}\right)\end{array}$ \\
\hline 1 & Sulphuric acid & Beer & 1.2 & Infinite \\
\hline $4 \mathrm{~s}$ & Fuel oil & Olive oil & 84 & 60 \\
\hline $4 \mathrm{v}$ & - & Syrup & 1500 & 70 \\
\hline $5 \mathrm{v}$ & - & Honey & 4000 & 85
\end{tabular}

Table 6 is a summary of the wash off times for a single head shower and body spray. The main conclusions that can be taken from these results are;

The arms have the shortest decontamination times, whilst the upper torso takes the longest. As expected the addition of the body spray reduces the decontamination time for the lower torso and leg region when compared with the wash off times for the single overhead shower head.

The rose and filmer designs have similar wash off performances, when compared with a single overhead shower, and the single overhead shower and body spray combination. It might have been expected that the wash off times would have been significantly reduced with the addition of the body spray, as in the case of the nozzle. Possible explanations for the similar times are in the application of the decontaminant which may have been applied slightly more thickly than in the case of the single overhead shower test. Another reason is that the method of supplying the water to the shower head and body spray may not have been suitable for the filmer and rose designs. The water supply to the overhead shower and the body spray is on a 'T-piece'. The shower rose designs produce a large pressure drop so takes more of the water than that of the body spray nozzle. There may be thus too little flow rate through the body spray to be optimally effective, therefore reducing the penetration and coverage of the body spray. For the body spray to be effectively used in conjunction with the shower rose and filmer designs, an independent water supply should be used.

The results also show that the upper legs and lower torso are particular problem areas in that they are usually the last areas to be decontaminated due to the water not reaching these areas effectively. It is therefore beneficial to have an overhead spray in conjunction with a body spray.

Due to the relatively quick wash off times of approximately three minutes for the most adhesive mixture, at a water temperature of $10^{\circ} \mathrm{C}$ it was decided not to increase the temperature as the mixture was adequately washed off and sufficient to enable comparison of the three shower head designs. It is expected that increasing the water temperature would have reduced these times further.

\section{CONCLUSIONS}

Droplet sizing has shown than the nozzle designs produce smaller droplets in the centre of the spray than the shower rose type of shower head. The force measurements also show that for the nozzle design the forces in the centre of the spray are greater than the shower rose and decrease towards the edges of the spray.

The testing of the eight shower heads highlighted deficiencies in their design to meet the proposed EU standard. All the designs do however conform to the less stringent ANSI standard which does not impose a volume of water to be collected within a certain radius, or a circumferential distribution based upon the mean volume of water collected. 
Table 4 Wash off test schedule

\begin{tabular}{lcccc} 
Shower head & $\begin{array}{c}\text { Non hazardous } \\
\text { substitute }\end{array}$ & $\begin{array}{c}\text { Flow rate } \\
(\mathbf{l} / \mathbf{m i n})\end{array}$ & $\begin{array}{c}\text { Water temp } \\
\left({ }^{\circ} \mathbf{C}\right)\end{array}$ & Body spray \\
\hline \multirow{4}{*}{ A_nozzle } & Beer & 60 & 10 & - \\
& Olive oil & 60 & 10 & - \\
& Syrup & 60 & 10 & - \\
& Honey & 60 & 10 & - \\
B_rose & Beer & 60 & 10 & - \\
& Olive oil & 60 & 10 & - \\
& Syrup & 60 & 10 & - \\
\hline C_filmer & Honey & 60 & 10 & - \\
\hline A_nozzle & Beer & 60 & 10 & - \\
\hline B_rose & Olive oil & 60 & 10 & $\sqrt{ }$ \\
\hline A_filmer & Olive oil & 110 & 10 & $\checkmark$ \\
\hline & Olive oil & 110 & 10 & $\checkmark$
\end{tabular}

Table 5 Decontamination times, overhead only (EU flow rate)

\begin{tabular}{lcccccccc} 
& & \multicolumn{6}{c}{ Decontamination time $(\mathbf{m i n s} / \mathbf{s e c})( \pm \mathbf{3 s e c})$} \\
\cline { 3 - 8 } $\begin{array}{l}\text { Shower } \\
\text { head }\end{array}$ & Hazard & \multicolumn{2}{c}{ Arms } & \multicolumn{2}{c}{ Legs } & \multicolumn{2}{c}{ Torso } & \\
\cline { 3 - 7 } substitute & Left & Right & Left & Right & Upper & Lower & Total Time \\
\hline \multirow{2}{*}{ A_nozzle } & Beer & 0.13 & 0.10 & 0.18 & 0.30 & 0.15 & 0.18 & 0.30 \\
& Olive oil & 2.20 & 2.35 & 4.10 & 2.50 & 2.40 & 2.55 & 4.10 \\
& Syrup & - & - & 1.45 & 1.30 & 2.05 & 2.20 & 2.20 \\
& Honey & 2.15 & 0.55 & 2.45 & 2.50 & 2.10 & 3.15 & 3.15 \\
\hline \multirow{4}{*}{ B_rose } & Beer & 0.15 & 0.25 & 0.30 & 0.43 & 0.17 & 0.33 & 0.43 \\
& Olive oil & 0.52 & 1.20 & 3.10 & 2.40 & 2.33 & 2.45 & 3.10 \\
& Syrup & - & - & 0.50 & 0.47 & 0.55 & 1.05 & 1.05 \\
& Honey & 0.47 & 0.55 & 2.33 & 1.27 & 2.48 & 3.20 & 3.20 \\
\hline C_filmer & Beer & 0.17 & 0.13 & 0.38 & 0.35 & 0.20 & 0.40 & 0.40 \\
& Olive oil & 1.45 & 2.30 & 2.50 & 2.10 & 1.55 & 3.10 & 3.10 \\
\hline
\end{tabular}

Table 6 Decontamination times, overhead and body spray combination (EU flow rate)

\begin{tabular}{|c|c|c|c|c|c|c|c|c|}
\hline \multirow{3}{*}{$\begin{array}{l}\text { Shower } \\
\text { head }\end{array}$} & \multirow{3}{*}{$\begin{array}{c}\text { Hazard } \\
\text { substitute }\end{array}$} & \multicolumn{7}{|c|}{ Decontamination time $(\mathrm{min} / \mathrm{sec})( \pm 3 \mathrm{sec})$} \\
\hline & & \multicolumn{2}{|c|}{ Arms } & \multicolumn{2}{|c|}{ Legs } & \multicolumn{2}{|c|}{ Torso } & \multirow[b]{2}{*}{ Total time } \\
\hline & & Left & Right & Left & Right & Upper & Lower & \\
\hline A_nozzle & Olive oil & 0.30 & 0.35 & 2.10 & 2.15 & 3.10 & 2.00 & 3.10 \\
\hline B_rose & Olive oil & 1.20 & 1.31 & 2.27 & 2.35 & 3.20 & 3.15 & 3.20 \\
\hline A_filmer & Olive oil & 2.10 & 2.20 & 3.28 & 3.10 & 3.05 & 3.15 & 3.28 \\
\hline
\end{tabular}


The wash off tests were carried out to ascertain which design, the 'shower rose' or the 'nozzle', is the most effective at decontaminating a person who has come into contact with an hazardous substance. From the results the shower rose design does perform well over a range of non hazardous substitutes, however when the nozzle is used in conjunction with the body spray the decontamination times are significantly reduced. This is highlighted when comparing the wash off times for the individual body parts between the nozzle and body spray combination with the other single overhead shower head designs.

The results also show that the upper legs and lower torso are particular problem areas to decontaminate; this is primarily due to the water not reaching these areas effectively. It would therefore be beneficial to have an overhead spray in conjunction with a body spray to ensure effective decontamination.

\section{REFERENCES}

[1] Chemical Safety Sheets, Samson Chemical Publishers, 1991.

[2] Jane's Chem-Bio Handbook, Jane's Information Group, April 2003.

[3] Dreisbach, R. H., Handbook of Poisoning, Blackwell Scientific Publications, 1971.

[4] Rimen, J. G., An Assessment of Fire Service Methods for Chemical Decontamination, Fire Research Developmet Group, Pub No. 9/94, 1994.

[5] Nasr, G, G., Yule, A, J and Bending, L., Industrial Sprays and Atomization, Springer-Verlag London Ltd, 2002.

[6] NFPA 750 Standard on Water Mist Fire Protection Systems, 2000 Edition.

[7] Minimax GmbH, Fine Water Spray Systems, Sonderdruck WS 5 aus dem Schadenmagazin der Albingia Versicherung.

[8] Coppalle, A., Fire Protection: Water Curtains, Fire Safety Journal, 241-255, 1993.

[9] Draft Content of New EU Standard on Laboratory Showers, Private communications, Mr Tony Hughes (M.D), Hughes Safety Showers Ltd., 2004.

[10] American National Standard for Emergency Eyewash and Shower Equipment, ANSI z358. 
